The high CA diet had no effect upon phosphorus utilization. Daily amounts of excreted, absorbed and retained calcium were increased whereas $\mathrm{Ca}$ absorption relative to intake was not significantly decreased in high $\mathrm{CA}$ fed pigs.

All signs of phosphorus deficiency such as hypophosphatemia, hypercalcemia, hypophosphaturia and hypercalciura appeared with both high and normal $\mathrm{Ca}$ diets though some of them, especially hypophosphatemia and hypercalcemia, were aggravated by the high $\mathrm{Ca}$ diet. Pigs fed this diet also exhibited decreased density and bending moment of bones without changes in their mineral contents as expressed in percent dry weight. However, ash content relative to bone volume (tibia) was lower and thus, osteoporosis was patent. In addition, higher liver weights and a trend to lower performance were observed with the high $\mathrm{Ca}$ diet. It was concluded that harmful effects of phosphorus deficiency are intensified by dietary $\mathrm{Ca}$ excess which therefore should not be recommended.

\title{
Effect of high and low phosphorus diets upon bones in the growing pig
}

\author{
Annie FOURDIN, Nicole FONTAINE, A. POINTILLART
}

INRA, Station de Recherches de Nutrition, 78350 Jouy-en-Josas

In various species, phosphorus deficiency, but also phosphorus excess may develop mineral and bone disorders. These disorders were studied in the growing pig by comparing the effects of three dietary phosphorus levels (from deficiency to excess) on some mineral metabolism parameters : urinary $\mathrm{Ca}$ and $\mathrm{P}$ excretions, plasma and bone mineral contents, bone bending moment and density. The low $\mathbf{P}$ diet $(0.4 \% \mathrm{P})$ was not supplemented with mineral $\mathrm{P}$, the high $\mathrm{P}$ diet $(1.2 \%$ $\mathrm{P}$ ) contained $0.4 \%$ plant $\mathrm{P}$ and $0.8 \%$ mineral $\mathrm{P}$ and the control diet $(0.7 \% \mathrm{P})$ around $60 \%$ plant $\mathrm{P}$ and $40 \%$ mineral $\mathrm{P}$. Ca $(0.8 \%)$ and vitamin $\mathrm{D}_{3}(500 \mathrm{IU} / \mathrm{kg}$ diet $)$ contents were the same for all diets. Animals were killed after a 7-week period.

P-deficient pigs exhibited hypophosphatemia, hypophosphaturia, higher plasma alkaline phosphatase, hypercalciuria as well as decreased mineral contents (about $-20 \%$ ), density and bending moment of all bones. The high P- diet did not change any plasma parameters, but provoked a very acute hyperphosphaturia, a severe nephrocalcinosis. It also decreased the strength of some bones (tibia, metatarsal), but did not change their mineral contents or density. In conclusion, the disorders in mineral metabolism are more marked with low than with high $\mathbf{P}$ diets. However, high P-related disorders should be taken into account in practical husbandry when formulating diets.

\section{Utilization of tandem rapeseed by weaned piglets and growing-finishing pigs}

\author{
F. GROSJEAN ${ }^{(1)}$, J. CASTAING ${ }^{(2)}$, J. FEKETE ${ }^{(1)}$, F. GATEL ${ }^{(1)}$
}

(I) I.T.C.F., 8, avenue du Président-Wilson, 75116 Paris.

(2) Association Générale des Producteurs de Maïs, 122, boulevard Tourasse, 64000 Pau.

The feeding value of Tandem rapeseed ( $52 \mu$ moles glucosinolate/g defatted dry matter) was studied in diets for $10-25 \mathrm{~kg}$ weaned piglets and for $27-102 \mathrm{~kg}$ growing-finishing pigs. Barley based diets containing either $0-5$ or $10 \%$ raw rapeseed or $20 \%$ extruded rapeseed were compared. These diets were formulated to supply $3.6 \mathrm{~g}$ lysine $/ 1000 \mathrm{kcal} \mathrm{DE}$ to piglets and $2.6 \mathrm{~g}$ to growingfinishing pigs. They were fed ad libitum to piglets and according to a feeding pattern to pigs.

In the piglet trial, energy intake was reduced by 3.4 and $4.1 \%$ with diets containing 5 and $10 \%$ raw rapeseed. With extruded rapeseed, energy intake was reduced by $5 \%$. Feed conversion ratio was similar whatever the diet. Consequently, growth of piglets mainly depended on the level of energy intake. 
In the growing-finishing pig trial, feeds including raw rapeseed were eaten more slowly than the control feed. Feed conversion ratio of diets containing 5 and $10 \%$ raw rapeseed was 5.3 and $9.1 \%$ higher than that of the control diet. The $10 \%$ extruded rapeseed diet led to the same results as the control diet. Fat content of carcasses was similar whatever the diet. By contrast, liver weight and consequently dressing percentage were affected by the presence of raw rapeseed in the diet.

\title{
Feeding value of barley-based fat enriched diets for weaned piglets
}

\author{
J. FEKETE ${ }^{(1)}$, F. GATEL ${ }^{(1)}$, J. CASTAING ${ }^{(2)}$, M. SEROUX ${ }^{(1)}$ \\ (1) I.T.C.F., 8, avenue du Président-Wilson, 75116 Paris. \\ (2) A.G.P.M., 122, boulevard Tourasse, 64000 Pau.
}

Three trials involving 1539 piglets weaned between 9 and $24 \mathrm{~kg}$ were conducted to study the effect of fat incorporation into barley-based diets. Different fat contents were tested : 3.5 and $7 \%$ animal fat (trial I), 10 and $20 \%$ extruded soybean seeds (trial II) and 2.5 and $5 \%$ soybean oil (trial III).

Feed conversion ratio decreased significantly with the increase in dietary fat content (or digestible energy content $)=-5 \%$ and $-6 \%$ with 3.5 and $7 \%$ fat, -2 and $-5 \%$ with 10 and $20 \%$ soybean seeds, -5 and $-7 \%$ with 2.5 and $5 \%$ soybean oil. This was obtained either by a decreased feed intake (with animal fat or $5 \%$ oil) or by a faster growth rate (with soybean seeds or $2.5 \%$ oil).

\section{Utilization of grain maize silages with or without cobs by the weaned piglet}

\author{
J. CASTAING ${ }^{(1)}$, R. COUDURE ${ }^{(1)}$, J. FEKETE ${ }^{(2)}$ \\ (1) A.G.P.M., 122, boulevard Tourasse, 64000 Pau. \\ (2) I.T.C.F., 8, avenue du Président-Wilson, 75116 Paris.
}

Four trials involving 1736 piglets between 9 and $25 \mathrm{~kg}$ live weight were made to study different maize silages supplemented with soybean meal and minerals and vitamins, Animals were fed ad libitum. In the first trial, moist grain maize silage (MGH) and maize grain silage with about $90 \%$ cobs (MGR 90) were compared to a control dry grain maize silage (MGS). In the second trial, the same diets were used as well as a fourth diet composed of maize silage $+100 \%$ cobs (MGR 100). In the third trial, finely ground MGR 90 (particle size : $0.63 \mathrm{~mm}$ ) and more coarsely ground MGR 90 (particle size : $0.83 \mathrm{~mm}$ ) were compared to dry grain maize. In the fourth trial, two varieties of maize were compared in MGH or MGR 90 silages. In each trial, silages came from the same field.

On an average and on the basis of the same water content of maize, feed intake was $2 \%$ higher with MGH than with MGS. Feed conversion ratios were similar with these two diets. MGR based diets led to a $2 \%$ higher feed intake than $\mathrm{MGH}$ based diets. Feed conversion ratio of MGR diets was $3 \%$ higher than that of MGH diets. Particle size of MGR 90 silages did not affect either feed intake or growth of the animals. There was no interaction between the type of silage (MGH or MGR 90) and the maize variety; thus performance of piglets were similar with both varieties. 